DOSIER

\title{
Las Líneas
}

fundamentales

de la filosofía

del derecho de

Hegel y la idea

de libertad

\section{The fundamental lines of Hegel's \\ philosophy of law and \\ the idea of freedom}

\author{
Raúl Reyes Camargo*
}

Universidad Nacional Autónoma de México, México raulreyesca84@gmail.com 


\title{
Resumen
}

El presente artículo sostiene que en Las líneas fundamentales de la filosofía del derecho es posible encontrar ideas inherentes al iusnaturalismo practicado en la Revolución francesa: libertad, igualdad, propiedad privada y voluntad general. Esto se expone mediante cuatro puntos. En el primero, se muestran los antecedentes de la Revolución francesa en la obra temprana de Hegel. En el segundo, se da testimonio de cómo podrían estar suturados los ideales de libertad e igualdad en la obra en cuestión. En el tercero, se muestra la forma en que podrían postularse en una monarquía constitucional. Por último, se destaca la figura polémica del monarca constitucional, la cual solucionaría el problema de la voluntad general propia del iusnaturalismo republicano.

Palabras clave: Filosofía del derecho, Filosofía de la historia, Iusnaturalismo; monarquía, república; libertad, igualdad y justicia,

\begin{abstract}
This article argues that in the Elements of philosophy of Right it is possible to find inherent ideas of the Iusnaturalism practiced in the French Revolution: liberty, equality, private property and general will. What is explained in four points. In the first, the background of the French Revolution in the early work of Hegel's shows. In the second, testimony given's to how the ideals of liberty and equality could be sutured in that work. In the third, the way in which these ideals could be postulated in a constitutional monarchy. Finally, the polemic figure of the constitutional monarch stands out, which would solve the problem of the general will of republican Iusnaturalism
\end{abstract}

KeYwords: Philosophy of Right, Philosophy of History, Iusnaturalism; monarchy, republic; liberty equality.

Recepción 06-12-19 / Aceptación 24-01-20 
* Raúl Reyes Camargo es doctor en Humanidades (Filosofía Política) por la Universidad Autónoma Metropolitana Iztapalapa (UAM-I) donde labora como docente. Sus principales áreas de trabajo son: la Ontología y Metafísica, la Filosofía Política y Moral, la Argumentación y la Ética. Ha coordinado libros arbitrados como Escritos sobre la filosofía política de György Lukács, México, (UAm-I Bonilla Artigas, 2019) donde colabora con el capítulo: "György Lukács y la dialéctica hegeliana”. Entre sus artículos de investigación destaca: "La teología política de tomas Müntzer" (Revista de Filosofía de la Universidad de Costa Rica, Núm. 149). 


\section{Introducción}

El presente trabajo pretende mostrar que la obra Lineas fundamentales de la filosofía del derecho contiene algunos ideales propios de la Revolución francesa: libertad, igualdad y voluntad general, los cuales se postulan en una monarquía constitucional "ideal", que pretende perfeccionar dichos planteamientos. Esto puede intuirse desde el título: Grundlinien der Philosophie des Rechts oder Naturrecht und Staatswissenschaft im Grundrisse (Lineas fundamentales de la filosofía del derecho o derecho natural y ciencia política), donde cabe subrayar la segunda parte, que sostiene la existencia de una relación entre la propuesta hegeliana y la del iusnaturalismo. Bobbio explica cómo se sostiene dicha relación:

Respecto a la tradición del derecho natural, la filosofía jurídica de Hegel es, a la vez, disolución y cumplimiento. Al hablar de "disolución" quiero decir que las categorías fundamentales que habían elaborado los iusnaturalistas para construir una teoría general del derecho y del Estado, las rechaza Hegel mediante una crítica, a menudo radical, que tiende a mostrar su inconsistencia y su insuficiencia. Al hablar de "cumplimiento" quiero decir que Hegel, en última instancia, tiende hacia la misma meta final, y la alcanza o cree alcanzarla justamente porque crea nuevos instrumentos, abandonando los viejos que se han vuelto ya inservibles. ${ }^{1}$

El argumento de Bobbio es interesante, denota una aparente contradicción que alejaría la posibilidad de que Hegel relanzara como meta los fines del iusnaturalismo; primero realizaría una crítica al derecho natural y, posteriormente, lo reinventaría. Esto es de suma importancia ya que

Norberto Bobbio, "Hegel y el iusnaturalismo", Diánonia, núm. 13. vol. 13 (1967): 55. Esta relación intelectual, hasta cierto punto, es análoga a la reinvención crítica de Marx a la filosofía hegeliana. 
las bases ideológicas de la Revolución francesa fueron conformadas por el iusnaturalismo, tal y como lo muestra Florance Gauthier. ${ }^{2}$ Bobbio resalta dos elementos importantes que Hegel discute con el iusnaturalismo, con el fin de lograr lo que la formulación iusnaturalista dejó pendiente: la libertad y la idea de voluntad general, las cuales forman parte de las tesis de este trabajo, con prioridad en la libertad.

Toda obra guarda una paradoja irresoluble: qué tanto influye en ella el contexto, o qué tanto puede separarse de su contexto superando la huella del autor. Terry Pinkard y Jacques D'hont alumbran las oscuridades que rondan el contexto de la obra hegeliana, incluso cuestionan la biografía hecha por uno de los discípulos de Hegel, Karl Rosenkranz, y le dan otras profundidades a su obra. Muchos conceptos hegelianos podrían entenderse mejor si se leen desde su contexto, entre ellos los aquí propuestos.

Dicha exégesis tiene como obstáculo los malentendidos alrededor de la obra hegeliana, alentados por mitos sobre que Hegel postuló una "monarquía constitucional", que las leyendas olvidaron adjetivar como "ideal". Se sostuvo que Hegel fue un filósofo al servicio de la monarquía despótica y que justificó el régimen de Federico II y Federico III.

En el prólogo de Lineas fundamentales de la filosofía del derecho se lee: "Lo que es racional, eso es efectivamente real; y lo que es efectivamente real, eso es racional". ${ }^{3}$ En el parágrafo 273: “c) de la subjetividad como la decisión última de la voluntad, el poder del príncipe. En el que los

Florance Gauthier, Triomphe et mort de Révolution des Droits de l'homme et du citoyen. 1789-17951802 (París: Éditions Syllepse, 2014).

Hegel, "Líneas fundamentales de la filosofía del derecho", en Hegel II, Ma. del Carmen Paredes Martín trad. y notas (Madrid: Gredos, 2010), 21. Si se revisa el escrito La Constitución de Alemania, se encuentra que Hegel diagnostica al imperio alemán como una nación sumamente divida, desorganizada, ante lo cual busca establecer una unificación "racional", mediante una constitución en la cual el monarca lograría dicha unidad. Hegel, La Constitución de Alemania, Dalmacio Negro Pavon, trad. (Madrid: Aguilar, 1972), 1-99. 
distintos poderes están conectados en una unidad individual, la cual es por consiguiente la cúspide y el comienzo de todo: la monarquía constitucional'. ${ }^{4}$ Este mito sería reforzado por la sentencia: lo que es racional es real; los hegelianos de derecha lo interpretaron como una justificación de los actos del Estado monárquico prusiano. En este texto escribe: "El Estado en cuanto realidad efectiva de la voluntad sustancial, realidad que él tiene en la autoconciencia, particular elevada a su universalidad, es lo racional en sí y para sî". 5 Entonces, sería muy fácil para sus contemporáneos y para algunos intérpretes sostener que Hegel justifica la monarquía a través de la "racionalidad de Estado". 6 Su actuar sería incuestionable debido a que el Estado está empatado con la universalidad de la razón, por ello tiene un poder absoluto y déspota sobre sus ciudadanos. $\mathrm{Si}$ a estas interpretaciones se agregan elementos del contexto, se podría

4 Hegel, "Líneas fundamentales de la filosofía del derecho", 252.

G.W.F Hegel, "Líneas fundamentales de la filosofía del derecho", \$258, 256

6 La frase: lo que es real es racional, se puede interpretar como una respuesta de Hegel a las disputas, y posteriormente se malinterpretó. La polémica entre Hegel y Fries ilustra la tesis que sostiene que la Filosofía del derecho adquiere más profundidad si su contenido se explica en función del contexto. Dicha polémica tiene lugar en el prólogo, pues se caracteriza a Fries como un "líder de esa insustancial brigada de los llamados filósofos" que producen una filosofía "superficial" y destructora de la sustancia del Estado. Fries divulgaba que Hegel buscaba basar todas las relaciones sociales en simples emociones, en lugar de fundarlas en el pensamiento racional, una idea que iba contra todo tipo de orden ético decente. Muchas de las afirmaciones de Hegel iban contra el mote fabricado por Fries. Incluso, en Ciencia de la lógica se localiza una crítica a la tesis de Fries que sostiene que la lógica tiene un antecedente antropológico (Hegel, Ciencia de la lógica, cuarta edición, Augusta y Rodolfo Mondolfo trad. (Buenos Aires: Solar Hachette 1974), 68-69. En el prólogo de las Lineas fundamentales de la filosofía del derecho rechaza la postura de Fries sobre el Estado en dos sentidos: uno que justifica la toma del poder por la pura volición subjetiva, es decir, tomar parte en el Estado sin más mediación que el puro querer; y el segundo que pretendía sustentarse en cierta filosofía cuya dirección no era una idea de verdad, sino un criterio individual (Hegel, "Líneas fundamentales de la filosofía del derecho", 15-16). Esa era la postura del monarca absoluto, él determina por sus voliciones lo que es verdadero para el Estado, mas no por lo verdadero, pues sólo lo racional es verdadero. El monarca "constitucional" postulado por Hegel sólo tiene que cumplir la ley, que es universal por derivarse del concepto. 
considerar que Napoleón Bonaparte fuera derrotado en Alemania y después inició la restauración de la monarquía alemana. Con estas tergiversaciones en la mira, es fácil creer que el autor de Fenomenología del espiritu en verdad fuera partidario de la restauración monárquica y que sus ideales filosóficos estuvieran empatados con lo despótico. Así lo infirió Rudolf Haym, uno de los primeros en sostener que Hegel era el filósofo del Estado prusiano, ${ }^{7}$ opinión que se ha vuelto mítica y ha acompañado el nombre de Hegel durante toda su historia. ${ }^{8}$

Postular una monarquía constitucional no impide plasmar los ideales de la Revolución francesa; habría que aclarar en qué sentido y cómo se puede argumentar que Hegel intenta incluir los ideales revolucionarios en dicha obra.

En sus textos juveniles se localizan ideales de la Revolución francesa que aparecerán en casi toda su obra, éstos son reinventados en las Lineas fundamentales de la filosofía del derecho: ${ }^{9}$ la libertad que se teje en relación con la propiedad privada; la igualdad y la voluntad colectiva y el derecho natural —este trabajo se centra en mostrar la existencia de una relación entre un evento histórico y la constitución de una obra polémica-. En la Filosofía de la historia Hegel confirma conocer dichos ideales y los rela-

Ver Rudolf Haym, Hegel und seine zeitung (Berlín: Rudolf Gaertner, 1857), 300-347.

8 Existe una colección importante de estudios en torno a los mitos sobre la filosofía de Hegel, ver Henning Otmman, "Hegel and Political Trends: A Criticism of the Politcial Hegel Legends", en Jon Stewart, The Hegel Myths and Legends (Evaston: Northwestern University Press, 1996).

9 Las opiniones sobre los ideales de la Revolución francesa varían, por ejemplo, para Hobsbawn sirvieron para instaurar la sociedad burguesa (Eric Hobsbawn, La era de la Revolución 1789-1848, Felipe Ximénez de Sandoval trad. [Ciudad de México: Paidós-Bocket, 2015], 9 y 73); para Furet más que ideales, la libertad y la igualdad eran términos jurídicos que emanaban de la misma necesidad de transición del régimen feudal al burgués (François Furet, La Revolution I 1770-1814 De turgot à Napoléon. [París: Pluriel, 2010], 128). Grothuysen y Gauthier, ubican los ideales de libertad, igualdad y derecho a la propiedad privada como conceptos surgidos del "naturalismo". Bernard Grothuysen, La filosofía de la Revolución francesa, Carlota Vallée trad. (Ciudad de México: EFE, 1988), 191-192. Gauthier, Triomphe et mort de Révolution, 5-50. 
ciona con la Declaración de los Derechos del Hombre y el Ciudadano y con el derecho natural, mismos que aparecen en la Constitución de 1791: ${ }^{10}$

Sin duda, en relación al principio formal se supusieron categorías ricas en contenido: primariamente la de la sociedad y de lo que resulta más provechoso. Sin embargo, el fin de la sociedad es político, es el Estado (Vid. Los derechos del hombre y el ciudadano, 1791) A saber: preservar los derechos naturales. El derecho natural, subrayo, es la libertad, y una nueva determinación de ésta la igualdad de derechos ante la ley. ${ }^{11}$

Mientras que en la Constitución francesa de 1791 se lee:

La Asamblea Nacional, al querer establecer la Constitución francesa sobre los principios que ella acaba de reconocer y declarar, suprime irrevocablemente las instituciones que herian la libertad y la igualdad de los derechos. [...]

-La Constitución garantiza, como derechos naturales y civiles:

-La Constitución garantiza la inviolabilidad de las propiedades $[\ldots]^{12}$

Es subrayable el hecho que en la Constitución de 1791, heredera de la subversión francesa de 1789, se postula una monarquía constitucional en donde el monarca queda reducido en sus funciones; algo similar ocurre

10 El trabajo de Florance Gauthier, insisto, es uno de los más importante sobre la relación entre el iusnaturalismo y la Revolución francesa. Para ella, la libertad y la igualdad son derechos naturales, mientras que la propiedad privada no.

11 Bei dem formellen Prinzip wurden wohl inhaltsvollere Kategorien herbeigebracht: also hauptsächlich die Gesellschaft und was nützlich für die Gesellschaft sei; aber der Zweck der Gesellschaft ist selbst politisch, der des Staats (s. Droits de l'homme et du citoyen, 1791), nämlich der, die natürlichen Rechte aufrechtzuerhalten; das natürliche Recht aber ist die Freiheit, und die weitere Bestimmung derselben ist die Gleichheit in den Rechten vor dem Gesetz. Traducción del autor. Hegel, Vorlesungen über die Philosophie der Geschichte. Werke 12 (Francfórt: Surkamp, 1986), 525.

12 J. Tulard et al. Historia y diccionario de la Revolución Francesa (Madrid: Crítica, 1984), 646-647. 
en la filosofía del derecho porque el monarca sólo coloca los puntos sobre las íes, un recurso para salvar el método dialéctico del mal infinito.

Por ello, tomaremos un solo hilo conductor: la relación tripartita entre ideales del iusnaturalismo, su práctica en la Revolución francesa y la evidencia de que Hegel abreva de ellos para su reflexión y discusión filosófica. El trabajo se divide en cuatro apartados: en el primero, se revisan algunos de los antecedentes más importantes sobre la postura de Hegel ante la Revolución francesa en los escritos anteriores a las Líneas fundamentales de la filosofía del derecho. El segundo, trata de los ideales de la Revolución francesa, entre los cuales sobresalen libertad e igualdad. En el tercero, se aborda la monarquía constitucional ideal como reino de la libertad; finalmente, en el cuarto, el monarca como interrupción del sistema dialéctico, cuya meta era resolver el problema de la voluntad universal, pues de ésta depende de la libertad.

\section{Los antecedentes de la Revolución francesa en la obra de Hegel}

Desde el periodo de Tubinga, se encuentran en la obra hegeliana temprana elementos emancipadores que se corresponden con los ideales iusnaturalistas practicados por la Revolución. En ese momento señaló que si un pueblo se apropia de cierta religión, ésta debe ser comandada por la libertad. ${ }^{13}$ Además, realizó una crítica a la religión cristiana con el fin de acabar con sus teólogos, quienes postulaban una religión no acorde con la libertad. De ahí que sostuviera como idea base la libertad, misma que conforma la Iglesia invisible. Pronunció como estandarte: “¿Que venga el 
Reino de Dios y no estemos mano sobre mano [...] Razón y libertad sigan siendo la consigna, y nuestro punto de unión a la Iglesia invisible". ${ }^{14}$ Posteriormente, en sus escritos de Berna, se encuentra una carta a Schelling, fechada el 16 de abril de 1795, donde sostiene que la filosofía ha de dar paso a la subversión:

Las consecuencias [de la obra El fundamento de la doctrina de la ciencia de Fichte] que se van a seguir asombrarán a ciertos señores. Va a dar vértigo esta suprema cumbre de toda la filosofía, que eleva de tal forma al hombre. Pero, ¿por qué se ha tardado tanto en revalorar la dignidad humana, en reconocer su capacidad de libertad, que le sitúa en un orden de igualdad con todos los espiritus? En mi opinión no hay mejor signo de nuestro tiempo que éste de que la humanidad se presente como tan digna de respeto en sí misma. Es una prueba de que desaparece el nimbo de las cabezas de los opresores y dioses de esta tierra. Los filósofos demuestran esa dignidad, los pueblos llegarán a sentirla $y$, en vez de exigir sus derechos pisoteados, se los volverán a tomar por si mismos. ${ }^{15}$

Libertad, igualdad y dignidad humana son ideas alumbradas por el filósofo para que los pueblos retomen sus derechos pisoteados; esto únicamente será posible mediante la subversión, el mejor signo de su tiempo, que no es otra más que la Revolución francesa. En un escrito casi contemporáneo a esta carta se lee la obvia preferencia por la república sobre la monarquía; para Hegel en una república ${ }^{16}$ se vive para una idea

14 Hegel, El joven Hegel. Ensayos y esbozos, José María Ripalda, editor y traductor. Madrid: EFE, 2014, 86. Para los efectos de este trabajo, hay que notar que razón y libertad son dos conceptos presentes durante casi toda su obra, incluso en los escritos de madurez, pero bajo nuevas determinaciones.

15 Hegel, Escritos de juventud, 57.

16 El término república aparecerá en los siguientes apartados: en el prefacio, una referencia a la república platónica; en la observación del $\$ 185$; en la del $\$ 279.2$; una referencia a la república en la observación del $\$ 331$. 
y sólo es realizable en ella; mientras que en la monarquía, se hace para un individuo (el monarca). Sólo el trabajo realizado bajo la égida de un ideal republicano encuentra su completa retribución espiritual. ${ }^{17}$

Otra pista importante es su primer escrito, publicado de forma anónima: el panfleto antibernés. ${ }^{18}$ Sólo se sabría su autoría tres años después de la muerte de Hegel. Supuestamente fue firmado por el abogado Jean Cart, su meta estribaba en recordarle a los seńores feudales la libertad de los ciudadanos del Vaud de Alemania.

En La positividad de la religión cristiana se desarrolla una profunda crítica a la realidad histórica: la fusión entre política (monarquía absoluta) y religión cristiana (catolicismo). Aquí Hegel cuestiona quién sería el tiranicida que salvara a Alemania. Terry Pinkard y Jacques D'hont -Díaz-Plaja en su libro Griegos y romanos en la Revolución francesa trata cómo el mundo clásico fue adoptado por el mundo revolucionariohan descrito que los deseos revolucionarios de Hegel se cifraban en la Revolución francesa mediante la mitología griega. Él mismo refiere a este uso en las Lecciones de Filosofía de la historia: ${ }^{19}$

Tal vez, con la excepción de Lutero para los protestantes, ¿qué héroes podríamos tener nosotros que nunca fuimos una nación? ¿Quién podría ser nuestro Teseo, que hubiera fundado un Estado y le hubiera dado sus leyes? ¿Dónde está nuestro Armodio y nuestro Aristogitón, a quienes pudiéramos cantar escolios como a libertadores de nuestra patria? ${ }^{20}$

17 Hegel, El joven Hegel, 99-100. No es de extrañarse que estas referencias a la subversión y la preferencia por la república coincidan con la república jacobina de 1792-1794. La carta parece celebrar dicho evento histórico.

18 Hegel, El joven Hegel, 352- 362. Se prefiere la siguiente versión: Hegel, Escritos de juventud, 183194.

19 Hegel, "Lecciones de filosofía de la historia", en Hegel II, Josep María Quintana Cabañas trad. (Madrid: Gredos, 1999), p.240.

20 Hegel, Escritos de juventud, 144-145. La figura de Lutero es importante en la filosofía hegeliana como antecedente de los personajes subversivos alemanes. No obstante, para los conocedores de la 
Las obras hasta aquí mencionadas no fueron publicadas en vida de Hegel, pero en ellas se percibe su postura a favor de la Revolución francesa; aunque indirectas, las referencias son claras. Una de las posibles razones para esta discreción hermética es la represión prusiana en cuanto a temas de la revolución; la publicación de un libro con contenidos diferentes al sistema político de la monarquía absoluta era más peligrosa que una carta con comentarios sobre los jacobinos. Esto no permite sostener que en su obra publicada Hegel conserve la postura revolucionaria, lo que sí es plausible es su profunda reflexión filosófica sobre y a partir de la Revolución francesa.

La reflexión sobre este evento histórico es visible en el apartado Die absolute Freiheit und der Schrecken "Libertad absoluta y el terror" de la Fenomenología del espiritu, referencia evidente al terror jacobino atribuido a Robespierre. El problema es abordado desde el proceso por el cual la conciencia deviene autoconciencia, y tiene que superar el momento de la Ilustración, donde todavía no se concebía la libertad en su integridad; esto sólo es posible mediante la negatividad absoluta, es decir, por un evento que irrumpe en la historia universal del espíritu.

El problema de la libertad absoluta se empata con el de la voluntad universal ${ }^{21}$ y la particular. La libertad absoluta se da cuando dicha voluntad se equipara con la particular; al final de cuentas, tiene más importancia

Reforma protestante fue un "rebelde conservador", pues cuando los campesinos exigieron derechos para sí y Lutero no pudo controlarlos, él mismo pidió a los príncipes masacrar a las masas que con anterioridad fueron aliadas de la Reforma protestante. Martín Lutero, Obras, Teófanes Egido, ed. (Salamanca: Sígueme, 2001), 275. Pese a las preferencias revolucionarias de Hegel, no resultaría extraño que existieran elementos conservadores en su filosofía mezclados con sus ímpetus revolucionarios.

21 Norberto Bobbio señala que Hegel retoma el concepto de voluntad general de la tradición iusnaturalista y, en un primer tiempo, lo convierte en Volksgeist (voluntad del pueblo); ésta no podía ser igual a la suma de las voluntades individuales o particulares. La voluntad tenía que obedecer a un factor universal y racional. Bobbio, "Hegel y el iusnaturalismo", 56-65. 
la voluntad colectiva, esta idea empata con el iusnaturalismo. El significado del concepto de libertad absoluta es el paso de la autoconciencia hasta devenir en espíritu libre y, posteriormente, traspasar a la esfera de la eticidad, a la vez, capaz de pensarse a sí misma y concebirse como sujeto. ${ }^{22} \mathrm{El}$ pasaje de la libertad absoluta se refiere al periodo de la república jacobina, esto se confirma en la Filosofía real (1806), escrito paralelo a Fenomenología del espiritu, publicado póstumamente.

La ventaja del gran hombre es precisamente que sabe y expresa la voluntad absoluta; alrededor de su bandera se congregan todos, en él tienen su dios. Así fundó Teseo la ciudad de Atenas, así en la Revolución francesa una terrible violencia mantuvo el Estado, el descarnado todo. Esta violencia no es despotismo sino tiranía, horrible dominación a secas; pero es necesaria y justa, en tanto constituye y mantiene el estado como este individuo real. ${ }^{23}$

Podría suponerse que se refiere a Napoleón, lo cual resulta dudoso porque el conquistador francés no ejerció una política de terror, y en las últimas dos referencias aquí expuestas se remite al terror. Robespierre y los jacobinos representan la figura del terror. Este fenómeno, para Hegel, va más allá del proceso de la historia de la autoconciencia, pues refiere el problema de la voluntad universal, sólo deviene mediante la negatividad absoluta manifiesta en la violencia revolucionaria, descrita como justa y necesaria. Es relevante subrayar dos cosas: la primera, la violencia de la "nueva" república jacobina, ésta declaró el terror contra sus enemigos, por ello mantuvo una figura política; la segunda, recuerda las paradojas de la Reforma protestante, donde las teologías políticas de Müntzer y Lutero justifican la muerte del enemigo mediante la violencia.

22 Hegel, Fenomenología del espiritu, en Hegel I, Antonio Gómez Ramos, trad. (Madrid: Gredos, Madrid, 2013), 487-496.

23 Hegel, Filosofía real, José María Ripalda, edición y traducción (Ciudad de México: FCE, 2008), 211. 
Así, se trazan las huellas de la Revolución y el problema de la libertad en Hegel, a pesar de no estar proferidas como su ideología, sí se presentan como elementos de su reflexión filosófica. El problema que sigue es plantearse si lo mismo ocurre con su filosofía del derecho.

\section{Los ideales de la Revolución francesa en las Líneas fundamentales de la filosofía del derecho}

Hay varias claves para leer a las Lineas fundamentales de la filosofía del derecho de Hegel, una de ellas es el ideal heredado de la Revolución francesa: la libertad. Ésta puede enriquecerse con su filosofía de la historia: en la sutura de ambas obras puede tejerse la hipótesis de que Hegel elabora su filosofía del derecho alrededor de la libertad: "El terreno del derecho es en general lo espiritual, y su lugar más próximo y su punto de partida la voluntad, que es libre, de modo que la libertad, constituye su esencia y determinación, y el sistema del derecho, es el reino de la libertad efectivamente realizada, el espíritu mismo como una segunda naturaleza”. ${ }^{24}$ Además, cuando trata la división del derecho según la voluntad en los diferentes momentos del silogismo (inmediata, singular y universal, expresada como libertad y eticidad), al momento de culminar con la eticidad realiza otro silogismo, con tres momentos, donde el tercero plantea una reflexión sobre la sutura entre libertad, historia y derecho: "el Estado, como la libertad que en la libre autonomía de la voluntad particular es al mismo tiempo universal y objetiva; este espíritu real y orgánico de $\alpha$ ) un pueblo, $\beta$ ) por medio de la relación de los espíritus de los pueblos particulares, $\gamma$ ) se revela y deviene efectivamente real en la historia universal

24 Hegel, "Líneas fundamentales de la filosofía del derecho", 38. 
como espíritu del mundo, cuyo derecho es el más elevado". ${ }^{25}$ Él mismo empata su filosofía del derecho con la de la historia, por lo cual resulta prudente observar qué entendía por libertad en una obra y en otra, y de dónde proviene la idea de libertad para el filósofo alemán.

Desde sus escritos juveniles, la idea de libertad proviene de la Revolución francesa, esto se confirma en su pensamiento maduro, como parte de la reflexión en Lecciones de la filosofía de la historia donde expresa muy bien cómo existe una correspondencia entre la filosofía y la Revolución francesa cómo ésta influyó en la filosofía y viceversa. ${ }^{26}$

El argumento es el siguiente: la libertad es la sustancia del espíritu, la filosofía especulativa aprende que todas las propiedades del espíritu subsisten gracias a la libertad, de ahí que la filosofía especulativa tenga como único criterio de verdad a la libertad: ${ }^{27}$

Lo único que interesa a la filosofía es el esplendor de la idea que brilla, y se refleja en la historia universal. La filosofía escapa no al tedio causado por los movimientos de las pasiones inmediatas en la realidad, para entregarse a la

Hegel, Principios de la filosofía del derecho, segunda edición, Juan Luis Vermal, traducción y prólogo (Barcelona, Edhasa 1999), 112. En el agregado del mismo parágrafo treinta y tres aclara que cuando habla de derecho, no alude meramente al derecho civil, sino también a la moralidad, la eticidad y la historia mundial. Hegel, Enciclopedia de las ciencias filosóficas en compendio, Ramón Valls Plana, trad. (Madrid: Alianza Editorial, 1999) y en el parágrafo quinientos treinta y seis, se vincula el Estado con la historia universal.

26 Hegel, "Lecciones de la filosofía de la historia", 769-785. Hegel escribe: "Se ha dicho que la Revolución francesa provino de la Filosofía; y no sin fundamento se ha llamado a la filosofía sabiduría mundana, pues ella no sólo es la verdad en sí y por sí, como pura esencia, sino también la verdad en cuanto se hace esencia, sino que es también la verdad en cuanto se hace viva en lo profano. No hay que mostrarse disconforme, pues, cuando se dice que la Revolución tuvo su primer incentivo en la filosofía. Pero esta filosofía comienza por ser únicamente pensamiento abstracto, no captación concreta de la verdad absoluta, en lo cual hay una inmensa realidad". Hegel, "Lecciones de la filosofía de la historia", 774. Posiblemente, la filosofía a la que refiere es el iusnaturalismo.

27 Hegel, "Lecciones de la filosofía de la historia", 330. 
contemplación; su interés estriba en conocer el progreso de la evolución de la Idea que se realiza, es decir, de la Idea de libertad, que existe sólo como conciencia de la libertad. ${ }^{28}$

Podría decirse la libertad es el único axioma de su sistema. Por lo tanto, si su filosofía se basa en la libertad, entonces lo hace en la concepción de libertad plasmada en la Constitución derivada de la Revolución francesa. Hace falta mostrar evidencias. Una de ellas aparece en la filosofía del espíritu de la Enciclopedia de las ciencias filosóficas en compendio, donde Hegel sostiene que la libertad y la justicia sólo pueden realizarse en la Constitución. En el $\$ 539$ se dedica un agregado al pensamiento sobre la libertad y la igualdad, que podría empatarse con la Constitución francesa de 1791:29

Libertad e igualdad son las categorías simples bajo las que corrientemente se resume lo que debiera constituir la determinación fundamental y el fin último y resultado de la constitución. Y eso es tan verdadero como que lo defectuoso de estas determinaciones es ante todo su índole enteramente abstracta. Si se retienen bajo esta forma de la abstracción, son precisamente ellas lo que impide conseguir lo concreto o lo destruyen, a saber, alguna [clase de] articulación del estado [en miembros diversificados], o sea, una constitución y gobierno en general. [...] Primeramente, por lo que se refiere a la igualdad, la afirmación corriente de que todos los seres humanos son iguales por naturaleza contiene el equívoco de confundir lo natural con el concepto; hay que decir que por naturaleza los seres humanos son sólo más bien todos desiguales. Pero el concepto de la libertad tal como primeramente EXISTE en cuanto tal, sin mayor determinación ni desarrollo, es la subjetividad abstracta como persona capaz de propiedad (\$488); esta única determinación

28 Hegel, "Líneas fundamentales de la filosofía del derecho", 785.

29 Hegel refiere que su texto y el tema de la libertad pueden abordarse desde esta obra. Hegel, Enciclopedia de las ciencias filosóficas en compendio, p. 77. 
abstracta de la personalidad constituye la igualdad efectivamente real de los seres humanos.

En este caso se cumple la sentencia de Bobbio: Hegel critica para superar el planteamiento, lo cual no implica su rechazo, de ahí que no difiera del iusnaturalismo. El pensamiento sólo es racional en la medida en que obedece a la libertad y la persigue. La libertad y la justicia se implican: "el espíritu o el hombre en cuanto tal es en sí libre", ${ }^{30}$ es decir, aquello que constituye al hombre, en su ser más íntimo, es la libertad y su conciencia. La autoconciencia de la libertad dimensiona su existencia, esto —en cuanto espíritu - es válido para todos, es un universal del espíritu, pues sólo se hace patente desde la racionalidad de la autoconciencia, presente como efectividad desde el "derecho" y mostrada por la filosofía del derecho desarrollada en la Enciclopedia de las ciencias filosóficas en compendio y en las Lineas fundamentales de la filosofía del derecho:

Pertenece a la formación, al pensar en cuanto conciencia del individuo en la forma de la universalidad, que yo sea concebido como persona universal, en la cual todos son idénticos. El ser humano vale asi porque es ser humano, no porque es judío, católico, protestante, alemán, italiano, etc. Esta conciencia para la cual el pensamiento tiene validez es de una importancia infinita y sólo es deficiente cuando, por ejemplo, se fija como cosmopolitismo, para oponerse a la vida concreta del Estado". ${ }^{31}$

En Lineas fundamentales de la filosofía del derecho queda plasmado y justificado filosóficamente el principio de igualdad: todos los hombres son iguales, tienen el mismo derecho a la libertad porque es algo inherente a cualquier hombre. Parece que en este punto la crítica a la igualdad

\footnotetext{
$30 \quad$ Hegel, "Lecciones de la filosofía de la historia", pp. 331.

31 Hegel, "Líneas fundamentales de la filosofía del derecho", 198-199.
} 
heredada del iusnaturalismo queda suspendida. Recordemos que la burguesía francesa, incluso la revolucionaria, no estaba dispuesta a aceptar las consecuencias de la igualdad universal de los hombres, tanto así que se resistían a liberar a los esclavos en las colonias; ${ }^{32}$ Hegel, en cambio, acepta las consecuencias de la igualdad universal.

Así, también se pueden encontrar muchos elementos que hacen pensar que las Lineas fundamentales de la filosofía del derecho se persigue los ideales de la Revolución francesa. La libertad tiene un papel fundamental en la formación de la autoconciencia, la cual está sometida a un proceso que llega a su cúspide cuando su libertad le es patente a sí misma —es decir, la autoconciencia se sabe a sí misma como libre y sabe que dicha determinación se llama libertad-, este desarrollo siempre ha sido de carácter histórico, tal y como lo muestra la Fenomenología del espiritu, por ello, en este tenor, no se podría aseverar que hay un sujeto sustraído del proceso histórico. Entonces, hay una clara unión entre la conciencia de la libertad y la historia, pero esa conexión es más profunda porque "La historia universal es el progreso en la conciencia de la libertad". ${ }^{33}$ De ahí que la historia comience con el mundo griego y su ideal de libertad, aún carente. No es hasta el cristianismo que el hombre es libre en cuanto que es hombre. En función de la libertad y la autoconciencia Hegel interpreta la historia de Europa, de ahí que el momento de la Revolución francesa sea importante para la historia universal —si es importante para

32 En este punto es interesante la hipótesis de Susan Buck-Morss, ella sostiene que Hegel deduce la dialéctica del Amo y del esclavo de la subversión de los esclavos de Haití, y que dicho evento muestra una mayor influencia en la filosofía hegeliana que la misma Revolución francesa. En todo caso, Hegel no sólo discute filosofías, sino que piensa los eventos más significativos de la historia: los ideales de libertad, igualdad y voluntad general, practicados en los procesos subversivos, muestran lo que las filosofías no previeron. En este caso su concepción de la filosofía del derecho también va a la zaga de la historia. Susan Buck-Morss, Hegel y Haití. La dialéctica del amo y esclavo. Una interpretación revolucionaria (Buenos Aires: Norma, 2005).

33 Hegel, "Lecciones de la filosofía de la historia", 330. 
la historia universal lo es para el espíritu; es decir, la Revolución francesa mostró al espíritu la libertad- pues su contenido no es otro que el de la libertad absoluta y el terror discutido en Fenomenología del espíritu.

En Lecciones de la filosofía de la historia se da seguimiento a la idea de libertad en diferentes pueblos. Un momento significativo de la Revolución francesa fue la realización de la libertad absoluta que concretó la aufhebung (superación) de la Ilustración, esto implicó el paso de la objetividad hasta concebirse como libre, a través de la libertad absoluta, principio abstracto que en su paso por la efectividad se convierte en libertad racional, plasmada en una Constitución y respaldada por un Estado. Se estableció una relación entre Constitución y formas de gobierno (república y monarquía constitucional), según el espíritu libertario de Francia, en tanto que la conciencia del pueblo francés, a través de su Estado y su constitución, giro alrededor de la idea de libertad. La Revolución francesa formó parte de los sucesos de la historia que incidieron en la autoconciencia. ${ }^{34}$

El ideal de libertad heredado de la Revolución francesa sería el principio bajo el cual se puede fundar el Estado y su derecho de forma legítima.

Con esto se ha encontrado, pues, un principio conceptual para el Estado. Tal principio no es ahora ya alguno procedente de opiniones, como cuando se apela al instinto social, a la necesidad de la seguridad de la propiedad; tampoco es un principio basado en ideas religiosas, como el que afirma el origen divino de la autoridad; sino que es el principio de la evidencia, la cual consiste en la identidad con mi autoconciencia, pero es todavía el principio de verdad, el cual es preciso distinguir bien del anterior. Éste es un enorme descubrimiento sobre lo más interior y la libertad. ${ }^{35}$

34 Hegel, "Lecciones de la filosofía de la historia", 765-780. También hay que considerar el papel de la libertad que le otorgó Hegel en la Fenomenología del espíritu, la Ciencia de la lógica. Enciclopedia de las ciencias filosóficas en compendio, $\$ 384$.

35 Hegel, "Lecciones de la filosofía de la historia", 774. 
Las Lineas fundamentales de la filosofía del derecho cumplen con su objetivo: darle forma a la libertad en la legalidad, proponiendo una Constitución dentro del Estado. Con ello, se puede sostener, a la par de Raya Dunayevskaya, que Hegel hace su filosofía desde la Revolución france$\mathrm{sa},{ }^{36}$ mas no comprende la Revolución en su teoría. Esta interpretación puede apoyarse en Joachim Ritter: "Así como el problema se planteó como su estandarte, así Hegel toma la idea de la libertad y la convierte en el elemento básico y en la materia exclusiva de su filosofía. Sin embargo, esto también significa, que de esta manera Hegel convierte a la filosofía en teoría de la época, en la que se le asigna la tarea de concebir la libertad política de la Revolución en su esencia; fundación sobre la cual todas las bases de la Revolución deben determinarse filosóficamente". ${ }^{37}$

\section{La monarquía constitucional, ideal de la libertad}

Nada exige que al postular algunos ideales de la Revolución francesa se tenga que hacer lo mismo con una república; pueden existir elementos republicanos en una monarquía constitucional e ideales monárquicos en

36 El pensamiento y el concepto de derecho se hicieron efectivos de una sola vez, contra esto no pudo ofrecer resistencia alguna el antiguo tinglado de injusticias. Ahora se ha redactado una constitución, teniendo presente el derecho, y es sobre este fundamento que debería de basarse todo. Hegel, "Líneas fundamentales de la filosofía del derecho", 774-775. Ver Raya Dunayevskaya, De Hegel a Sartre y de Marx a Mao, Ofelia Castillo, Aníbal Leal y Marcela Suárez, trad. (Ciudad de México: Prometeo Liberado, 2012), 424-425 y Raya Dunayevskaya, El poder de la negatividad, Félix Valdés García, Miguel de Armas, trads. (Ciudad de México: Juan Pablos Editor, 2009),1-67.

37 Joachim Ritter, Hegel and French Revolution, Richard Die Winfield, traducción e introducción (Cambridge: The Massachuttes Institute de Tecnology, 1982), 48. "Just as the problem raised it as their banner, so Hegel take up the idea of freedom and makes it the basic element and sole matter his philosophy. This also signifies, however, that Hegel in this way makes philosophy the theory of the age it is given the task of conceiving the political freedom of the Revolution in its essence; the foundation upon which The Revolution "bases all” shall be philosophically determined", traducción del autor. 
una república, tal y como lo mostraron las constituciones de 1791 y la de 1795.

En la Filosofia de la historia, Hegel piensa la Revolución como un acontecimiento histórico con sus diferentes momentos, pero en otras obras no cesa de repetir que es el evento consagrado alrededor de la libertad. ${ }^{38}$ Él hace filosofía con los procesos de la historia. Únicamente en este sentido se puede decir que elucubra el proceso de restauración de la monarquía alemana, que lo lleva a comprender una paradoja planteada por cualquier evento revolucionario: después de una subversión tiene que instaurarse la ley de la Constitución. El estado de excepción que impone una Revolución no puede durar, pues el poder del Estado no reside en la voluntad individual. Esta versión, por su propia naturaleza argumentativa, conduce a cuestionar la existencia del Estado en un proceso revolucionario sustentado en una voluntad individual, ${ }^{39}$ pues ella transforma al Estado según el "derecho". La monarquía feudal francesa se construyó con base en principios abstractos, depositando el poder en una voluntad individual. Esto no era compartido por su religión oficial y por ello Luis XVI fue derrocado por la Revolución. ${ }^{40}$ En otras palabras, el Estado francés fue construido bajo la estructura de principios filosóficos abstractos, la cual elevaba la figura del monarca a una cúspide, desde donde gobernaba con su séquito. El poder legislativo, en lugar de hacer leyes, se dedicaba a los asuntos administrativos y propios del poder judicial. Tal

38 Hegel, "Líneas fundamentales de la filosofía del derecho", 80.

39 Hegel, "Lecciones de la filosofía de la historia", 777-778.

40 Esto recuerda claramente el ideal de Jena, de aquellos revolucionarios girondinos entre los que se encontraban Höldering y Schelling que buscaban un cambio espiritual, político, religioso y curiosamente filosófico en su país. Podría entenderse entonces que Hegel no propone principios filosóficos abstractos, sino que su planteamiento tendría que ver con la realidad. Sólo hay pequeñas orientaciones en los escritos de Jena, pero cómo saber si Hegel los mantuvo o en qué consiste esta filosofía que llevará a la crisis política. No por nada Dunayevskaya, Ruben Dri y Ricther ven en la obra de Hegel una filosofía que lucha por la libertad. 
irracionalidad no contó con el apoyo del clero ni la ayuda de la nación entera, por ello fue derrocado el gobierno monárquico despótico francés.

Una vez que derrocó al poder opresor, la Revolución debió haber transferido el poder al pueblo, pero éste cayó en la Convención Nacional y en sus comités. "En estos momentos dominan los principios abstractos de libertad y — tal y como ésta se ofrece a la voluntad subjetiva- de virtud' ${ }^{41}$ El problema radica en que no hay parangón con el cual juzgar la virtud más que la virtud misma. De ahí que el discurso alrededor de la virtud sea cuestionable, pues ésta y la suspicacia llevaron al monarca francés a ser derrocado. La virtud en la "conciencia" del monarca estaba potenciada por la religión católica. Robespierre ${ }^{42}$ también cayó por sustentarse en la virtud. ${ }^{43} \mathrm{El}$ mensaje es: el poder, sea revolucionario o monárquico, no puede sustentarse en la virtud, ha de ser en la racionalidad y en lo absoluto.

Pareciera que el concepto de libertad robesperiano estaba contra el sano juicio de la razón. A Hegel le importa más el camino de la transferencia del poder que el juicio moral a Robespierre. Una vez caído el gobierno del "tirano de la virtud" el poder pasó a una forma parecida a la anterior, la diferencia estribaba en que la cúspide del poder fue tomada por cinco personas que conformaron una persona moral. Este gobierno, a su vez, estuvo bajo la tutela de asambleas legislativas, mismas que sólo tuvieron como consecuencia un nuevo relevo del poder, lo cual demostró la imperiosa necesidad de que gobernara un poder con racionalidad.

Napoleón sería ese poder, se impuso como una voluntad general y trajo consigo instituciones liberales; supo controlar el desorden que había

41 Hegel, "Lecciones de la filosofía de la historia", 778.

42 Aunque el lenguaje de Hegel en este escrito aparece como "emocional", en otros muestra un tratamiento neutro, pues exhibe el conocimiento de la constitución que propuso Robespierre para la democracia francesa. Hegel, "On the English Reform Bill", en Hegel, Political Writings, H.B. Nisbet, trad. (Cambridge: Cambridge University Press, 1999), 258.

43 Hegel, "Lecciones de la filosofía de la historia", 779. 
imperado en los lugares donde antes no existían dichas instituciones. Europa entera se habría beneficiado con el poder que estableció Napoleón, pero: "Jamás se obtuvieron mayores victorias, jamás se realizaron unas expediciones más geniales, pero nunca se manifestó una luz más clara que la impotencia de la victoria”. ${ }^{44}$ Aparentemente, Napoleón ocupaba un lugar solar en dicha cita, pero es de suma importancia el proceso, pues Hegel señala la impotencia de la victoria misma, no se subraya la persona sino en el hecho mismo. Napoleón fue derrotado y regresó al poder la monarquía constitucional. Esto no fue suficiente, pareciera que Hegel critica a la monarquía constitucional:

El sentir de los pueblos, es decir, su sentimiento religioso y el de su nacionalidad, derribó finalmente a este coloso, y en Francia se instituyó de nuevo una monarquía constitucional, sobre la base de la Carta [Constitución]. Pero en ella se manifestó una vez más la oposición entre los sentimientos y la desconfianza. Los franceses se engañaron a si mismos cuando proclamaban su adhesión a la monarquía, manifestándole rendimiento y amor y llenándola de bendiciones. Se presentó una farsa que duró más de quince años. Pues aun cuando la Carta fue el pendón general y las dos partes del sentir eran católicas y en ella se hizo caso de conciencia el aniquilar las instituciones existentes. Con esto tuvo lugar un nuevo hundimiento y el gobierno fue derribado. ${ }^{45}$

Esto parece contrastar con la hipótesis de que Hegel retoma la Constitución francesa de 1791, pero se observa un momento de autocrítica. Lo destacable es el rol de la monarquía constitucional después de postularla en las Lineas fundamentales de la filosofía del derecho como la mejor forma de gobierno. Ahora aparece como un posible engaño, aunque líneas más adelante reconoce que el problema también está del lado de la "voluntad

\footnotetext{
44 Hegel, "Lecciones de la filosofía de la historia", 779.

45 Hegel, "Lecciones de la filosofía de la historia", 779-780.
} 
subjetiva”. Esto se explica porque la monarquía constitucional propuesta por Hegel es ideal y da un lineamiento que apunta hacia la libertad, trata de superar al iusnaturalismo mediante la universalidad de lo racional. Esta operación recuerda el estandarte de la iglesia invisible.

En un movimiento dialéctico, al parecer, realiza la autocrítica a lo escrito sobre la monarquía constitucional, ésta consiste en sostener que la voluntad universal no necesariamente proviene de la voluntad empíricamente universal. Es decir, se refiere a que los individuos tomen el poder o sean parte del régimen. En este punto hace un señalamiento al liberalismo, doctrina donde prevalecen los derechos racionales, la propiedad privada, la participación ciudadana en los asuntos del Estado. El liberalismo opone los átomos de las voluntades individuales a la voluntad general, pues todo debe hacerse según su voluntad y su expreso consentimiento. El problema con las voluntades individuales es que su idea de libertad — que potencia su actuar — impide la conformación de una organización política sólida. El gobierno ha de enfrentar muchas oposiciones; dimanan divergencias particulares, por lo que estas oposiciones son arbitrarias. Hegel toma partido en apariencia: estaría en contra de los ideales liberales y republicanos de la Revolución. Va al centro del problema que detiene la historia: en la representación de la voluntad, sea en una monarquía constitucional o una república democrática, tiene que prevalecer la voluntad universal, la libertad en sí y por sí.

La voluntad de los muchos derriba el ministerio, y entran ahora en él los que hasta este momento habían constituido la oposición; pero ésta, en tanto que ahora es el gobierno, tiene a su vez a los muchos en contra suya. $\mathrm{Y}$ va continuando así el movimiento y la inquietud. Esta colisión, este nudo, este problema es aquello en lo que se detiene la historia y que ésta ha de resolverse en tiempos futuros. ${ }^{46}$

46 Hegel, "Lecciones de la filosofía de la historia", 780. 
Ni la monarquía constitucional ni el sistema democrático convencieron a Hegel. La historia queda detenida; después de la Revolución francesa, la restauración no concretó nada bueno ni logró superar aquello que la revolución "no pudo". La libertad política por la cual se preocupa Hegel es, en realidad, paradójica; pero no puede renunciar a ella.

Agregado. El principio del mundo moderno es la libertad de la subjetividad, el que todos los aspectos sustanciales que existen en la totalidad espiritual se desarrollen y alcancen su derecho. Si se parte de este punto de vista no se podrá plantear la ociosa pregunta acerca de si la mejor forma es la monarquía o la democracia. Sólo puede decirse que son unilaterales todas las constituciones políticas que no puedan soportar en su interior el principio de la libre subjetividad y no sepan corresponder a una razón cultivada. ${ }^{47}$

\section{El monarca: concepto introducido a la fuerza en las Líneas fundamentales de la filosofia del derecho.}

La dialéctica hegeliana como método es una característica propia de la filosofía. Con ella se intenta superar el romanticismo e idealismo alemán, pues sería el instrumento de reflexión que permitiría a Hegel ir más allá de los contenidos de la Ilustración y de las filosofías antecesoras. ${ }^{48}$ En las Lineas fundamentales de la filosofía del derecho la figura del monarca y la monarquía se introducen artificialmente, es decir, se fuerza el mismo método dialéctico.

$47 \quad$ Hegel, Principios de la filosofía del derecho, 417.

48 Esta situación la muestran Raya Duyanevskaya y Georg Lukács; aunque Lukács se centra más en las relaciones del contexto y la obra, aún así muestra un Hegel que comparte muchos ideales con la Revolución francesa. Georg Lukács, El joven Hegel y los problemas de la sociedad capitalista, Manuel Sacristán, trad. (Barcelona: Grijalbo, 1970). 
Hegel postula que el Estado, en sus tres momentos, conforma un silogismo según el método dialéctico: a) derecho político interno, $b$ ) derecho político externo, $c$ ) la historia universal. De éstos, explorará el momento del derecho político interno que se divide en Constitución interna para sí, en la cual hay tres momentos importantes: 1. el poder del príncipe, 2. el poder gubernativo, 3. el poder legislativo; el centro es el poder del príncipe.

En la constitución política hegeliana, el Estado es la realidad efectiva de la idea ética. Lo primordial es su momento de voluntad sustancial, elevada a la universalidad por mediación de la autoconciencia: es la racionalidad en sí y para sí. La libertad es la idea que dota el momento universal y el único contenido de su finalidad, de su objetivo. Ella está ubicada en el derecho político interno. En esta esfera habla de la efectividad concreta de la libertad; no obstante, enfrenta la siguiente contradicción: por un lado, los intereses individuales y el reconocimiento de su derecho; por el otro, el derecho universal bajo el cual se sustenta el Estado — la libertad individual—chocará muchas veces con los intereses del Estado, pues él es una fuerza superior y extrínseca a ellos. "Pero por otra parte, él es su finalidad inmanente y tiene su fuerza en la unidad de su fin último universal y de los intereses particulares de los individuos, en cuanto que éstos tienen deberes frente a él en la medida en que a la vez tienen derechos". ${ }^{49}$

La existencia del Estado está dirigida a la libertad, tanto en la esfera de lo particular como en la de lo universal; pero este fin no puede lograrse por sí mismo si no existe la mediación de una Constitución. Ésta es la forma en que el Estado se concibe a sí mismo hacia adentro, su propia reflexión de sí mismo. También, una personalidad formada hacia el exterior, en un ir fuera de sí. Es la única manera en que la idealidad surgida

49 Hegel, "Líneas fundamentales de la filosofía del derecho", 233. 
desde dentro puede tener forma. Es racional por sí misma, no puede ser de otro modo, sino cómo lograría la conciliación entre los intereses particulares y los del Estado, cuyo objetivo es concretar la libertad. Esta racionalidad proviene de la naturaleza del concepto. En este punto comienzan los problemas dialécticos. Hegel reconoce que se deben buscar tres momentos dialécticos: universalidad, particularidad e individualidad, pero en los agregados hay una aclaración muy importante: "Cuando corrientemente se habla de tres poderes, el legislativo, el ejecutivo y el judicial, el primero corresponde a la universalidad y el segundo a la particularidad; el judicial, en cambio, no es el tercer momento del concepto, ya que su individualidad está fuera de aquellas esferas". ${ }^{50}$ Aquí comienza la ruina de la marcha dialéctica. De igual forma se entiende por qué Hegel agrega un monarca en la organización del Estado ideal, pues:

$\$ 273$. El Estado político se divide entonces en las siguientes diferencias sustanciales:

a) el poder de determinar y establecer lo universal: el poder legislativo;

b) la subsunción de las esferas particulares y los casos individuales bajo lo universal: el poder gubernativo;

c) la subjetividad como decisión última de la voluntad: el poder del príncipe. En él se reúnen los diferentes poderes en una unidad individual, que es por lo tanto la culminación y el comienzo de todo, y constituye la monarquía constitucional..$^{51}$

El poder del monarca se inscribe dentro de la subjetividad que precisamente dota al Estado de individualidad. El monarca es un recurso teórico que trata de salvar el silogismo hegeliano. Como menciona Rubén Dri, este pasaje refiere a los momentos mediante los cuales se pasa de la 
sustancia a la causa, y de la causa al pasaje del sujeto $;^{52}$ se pasa de la sustancia del Estado a su personalidad.

Más adelante, Hegel reconoce otras formas de gobierno: democracia, aristocracia y monarquía, pero éstas le son indiferentes, puesto que sólo se pueden abordar de un modo histórico, porque no son suficientes para alcanzar su desarrollo dialéctico y racional, lo que garantizaría la libertad. De ahí que argumente que la monarquía constitucional no ha ostentado un lugar en la historia, pero sí tiene un papel crítico ante la monarquía alemana, que sí posee lugar en la historia que estaba escribiéndose.

Pasando a la cuestión del gobernante, Hegel postula un príncipe; tiene la estructura de ser el soberano en quien recae la decisión última, muy alejado de un príncipe feudal, aunque si se procede por sistema es fácil mostrarlo. El punto es demostrar que desde el método, la dialéctica, no se refiera a un poder feudal, sino a una figura política en la que recae la decisión excepcional: el poder de decidir del soberano. El príncipe es la reunión de los tres momentos del silogismo dialéctico: el universal con el poder legislativo, pues junta la universalidad de las leyes y de la constitución; el momento particular con el poder gubernativo, pues son los momentos consultivos, y el de la decisión última: por ello el poder (voluntad) del monarca tiene la negatividad referida a sí misma. ${ }^{53}$ Esta propiedad permite la autodeterminación, tanto hacia fuera como hacia dentro, es la soberanía del Estado, en quien reside la decisión última, en su relación con los diferentes países y hacia el interior. El príncipe tiene la última palabra en los asuntos nacionales pero, si se pone atención, la figura del monarca no se deduce, sino que es introducida por la fuerza de la negatividad, por ello también rompe el proceso deductivo hegeliano, y quedaría fuera del sistema. El monarca es un elemento que aparece en el sistema hegeliano, pero está de más. Dicha figura describe en manos

\footnotetext{
52 Rubén Dri, La rosa en la cruz. La filosofia politica hegeliana (Buenos Aires: Biblos, 2009), 196.

53 Hegel, Principios de la filosofía del derecho, 422.
} 
de quién ha de quedar el poder soberano, el cual está referido a sí mismo mediante la negatividad, de lo contrario, ya no sería soberano, pero:

El hecho de que la soberanía sea la idealidad de toda legitimación particular puede llevar a que se confunda, como de hecho ocurre con frecuencia, con el mero poder y el vacío arbitrio, y que se tomen los términos soberanía y despotismo como sinónimos [...] La soberanía constituye, por el contrario, en una situación legal y constitucional, el momento de la idealidad. ${ }^{54}$

Así, se evidencia que el monarca hegeliano ocupa el lugar del soberano; su método da cuenta de la autorreferencialidad implícita de cualquier poder gubernativo (ejecutivo) el cual, en ciertas situaciones, tiene la tarea de tomar una decisión. El problema del monarca y lo que implica el momento de la decisión última es el más difícil para el raciocinio, porque permanece en determinaciones aisladas; ${ }^{55}$ precisamente al ser un término introducido por la fuerza en la dialéctica. El monarca sólo tiene la tarea de hacer cumplir la ley que emana del concepto, aunque sea un forastero del reino dialéctico. La ley dicta la libertad y la igualdad que han superado, en apariencia, al iusnaturalismo y, con ello, a los problemas que trajo consigo la Revolución francesa, pero que por las circunstancias históricas no se concretaron.

El monarca y la monarquía intentan resolver un problema heredado del iusnaturalismo practicado en la Revolución francesa: cómo poner dentro de la ley la posibilidad de que predomine la voluntad general (universal, racional, en sí y por sí), pues ella no puede ser únicamente la voluntad de los muchos, debe ser la voluntad universal en sí y para sí. Quizá por ello Hegel postuló una monarquía constitucional en la cual el soberano somete las voluntades individuales a lo racional y lo universal.

Hegel, Principios de la filosofía del derecho, 422.

Hegel, Principios de la filosofía del derecho, \$279.2, 425 


\section{Conclusión}

La posibilidad planteada es la siguiente: en las Lineas fundamentales del derecho Hegel retoma, discute y reinventa las siguientes categorías del iusnaturalismo: libertad, igualdad, propiedad privada y voluntad general. Aquí no tratamos la propiedad privada porque ésta incluye, además, la reflexión de la economía política de Adam Smith. ${ }^{56} \mathrm{La}$ forma en que retoma estos ideales, en un primer tiempo, parece sólo provenir de la discusión con el iusnaturalismo, pero las obras a las que él mismo refiere en su filosofía del derecho permiten contextualizar que su referente es la Revolución francesa. En un segundo tiempo, Hegel discute con la tradición y pretende perfeccionar dichos ideales, quedando de la siguiente forma:

La libertad en la filosofía del derecho consiste en obedecer la ley, pero ésta desciende desde lo más alto del espíritu absoluto, de la eticidad, de la voluntad en sí, racional, universal.

En cuanto a la igualdad, Hegel menciona que se teje alrededor de la propiedad privada. En otro pasaje citado, su planteamiento no parece distanciarse ni un ápice del iusnaturalismo, pues un humano vale por ser humano.

La libertad, comandada por la voluntad general, en esta polémica obra sólo puede ser "racional" en una monarquía constitucional ideal, aunque conlleva una crítica a la monarquía despótica histórica y de su tiempo. Eso explicaría por qué Hegel, en otros topos de su sistema, sostiene que es una pérdida de tiempo preguntarse cuál forma de gobierno es mejor, si la monarquía o la democracia, y de ahí el reproche a la Revolución francesa por haberse adherido a una monarquía constitucional.

La monarquía constitucional de Hegel postula un monarca, lo introduce a la fuerza en la dialéctica, a fin de que diga "yo quiero", un querer

56 Claudio Mario Aliscioni, El capital en Hegel. Estudios sobre la lógica económica de la Filosofía del derecho (Argentina: Homo sapiens, 2010). 
de la ley más universal, es un sirviente del concepto. El propósito es unificar las voluntades particulares e individuales a la universal, para salvaguardar la libertad que ha superado al iusnaturalismo y a las doctrinas filosóficas. Otras funciones que quizá ponga en cuestión la monarquía hegeliana son que en el monarca reside la decisión última, pero ésta es la función de cualquier gobernante. Además, sólo puede decidir lo que la ley le permite. 


\section{Referencias}

Aliscioni, Claudio Mario. El capital en Hegel. Estudios sobre la lógica económica de la Filosofía del derecho. Argentina: Homo sapiens, 2010.

Bobbia, Noberto. "Hegel y el Iusnaturalismo". Diánonia, núm. 13. vol. 13, (1967): 55-78.

Buck-Morss, S. Hegel y Haiti. La dialéctica del amo y esclavo. Una interpretación revolucionaria. Buenos Aires: Norma, 2005.

Dri, Rubén. La rosa en la cruz. La filosofía política hegeliana. Buenos Aires: Biblos, 2009.

Dunayevskaya, Raya. El poder de la negatividad. Félix Valdés García, Miguel de Armas ed. Ciudad de México: Juan Pablos Editor, 2009.

. De Hegel a Sartre y de Marx a Mao. Ofelia Castillo, Aníbal Leal y Marcela Suárez trad. Ciudad de México: Prometeo Liberado, 2012.

D’hondt, Jacques. Hegel. Carlos Pujol trad. Ciudad de México: Tusquets, 2013.

Furet, François. La Revolution I 1770-1814 De turgot à Napoléon. París: Pluriel, 2010.

Gauthier, Florance. Triomphe et mort de Révolution des Droits de l'homme et du citoyen. 1789-1795-1802. París: Éditions Syllepse, 2014.

Grothuysen, Bernard. La filosofía de la Revolución francesa. Carlota Vallée trad. Ciudad de México: EFE, 1988.

Haym, Rudolf. Hegel und seine zeitung. Berlín: Rudolf Gaertner, 1857.

Hegel, La Constitución de Alemania. Dalmacio Negro Pavon trad. Madrid: Aguilar, 1972.

. Ciencia de la lógica, cuarta edición. Augusta y Rodolfo Mondolfo trad. Buenos Aires: Solar Hachette, 1974.

. Escritos de juventud. José María Ripalda y Zoltan Szankay trad. Madrid: EFE, 1978. 
. Vorlesungen über die Philosophie der Geschichte. Werke 12. Francfórt: Surkamp, 1986.

. The letters. Clark Butler y Christiane Seiler trads. Bloomington: Indiana University Press, 1984.

- Principios de la filosofía del derecho, segunda edición. Juan Luis

Vermal traducción y prólogo. Barcelona: Edhasa, 1999.

- Enciclopedia de las ciencias filosóficas en compendio. Ramón Valls Plana trad. Madrid: Alianza editorial, 1999.

. On the English Reform Bill. En: Politicals Writings. H.B. Nisbet trad. Cambridge: Cambridge University Press, 1999.

. Filosofía Real. José Maria Ripalda trad. México: FCE, 2008.

. "Lecciones de la filosofía de la historia". En Hegel II. Josep María

Quintana Cabañas, traductor. Madrid: Gredos, 2010.

- Lineas fundamentales de la filosofía del derecho En: Hegel II, Ma.

del Carmen Paredes Martín edición, traducción y notas. Madrid: Gredos, 2010.

. Fenomenología del espiritu. En: Hegel I. Antonio Gómez Ramos trad. Madrid: Gredos, 2013.

. El joven Hegel. Ensayos y esbozos. José María Ripalda edición y traducción. Madrid: EFE, 2014.

Otmman, Henning. "Hegel and Political Trends: A Criticism of the Political Hegel Legends". En: Jon Stewart. The Hegel Myths and Legends. Evaston: Northwestern University Press, 1996.

Hobsbawn, Eric. La era de la Revolución 1789-1848. Felipe Ximénez de Sandoval trad. Ciudad de México: Paidós-Bocket, 2015.

Lukács, Georg. El joven Hegel y los problemas de la sociedad capitalista. Manuel Sacristán trad. Barcelona: Grijalbo, 1970.

Lutero, Martín. Obras. Teófanes Egido ed. Salamanca: Sígueme, 2001.

Pérez Cortés, Sergio. La política del concepto. Ciudad de México: UAM, 1989.

Pinkard, Terry. Hegel. Una biografía. Madrid, Acento, 2002. 
Tulard, J. et al. Historia y diccionario de la Revolución Francesa. Madrid: Crítica, 1984.

Ritter, Joachmin. Hegel and French Revolution. Richard Die Winfield trad. Cambridge: The Massachuttes Institute de Tecnology, 1982. 